\title{
Donación de órganos y trasplantes en México, ¿todo está resuelto?
}

\section{Organ donation and transplantation in Mexico, is everything solved?}

\author{
Rubén Argüero-Sánchez, ${ }^{\text {* }}$ Omar Sánchez-Ramírez y Enrique M. Olivares-Durán² \\ 'Universidad Nacional Autónoma de México, Facultad de Medicina, Departamento de Cirugía, Ciudad de México; ²Instituto Mexicano del Seguro \\ Social, Centro Médico Nacional del Bajío, Hospital de Especialidades 1, Guanajuato. México
}

En 1954, en Boston, Estados Unidos, se realizó el primer trasplante renal exitoso en humanos. En 1963, en ese mismo país, Hardy llevó a cabo el primer trasplante pulmonar y Starzl, el primer trasplante hepático. En 1967, en Sudáfrica, Barnard efectuó el primer trasplante de corazón.

En México, en 1963, los doctores Manuel Quijano, Regino Ronces, Federico Ortiz Quezada y Francisco Gómez Mont realizaron el primer trasplante renal a partir de un donador vivo en el Centro Médico Nacional (CMN) del Instituto Mexicano del Seguro Social (IMSS), hoy CMN Siglo XXI. En 1976, en el Instituto Nacional de la Nutrición (actualmente Instituto Nacional de Ciencias Médicas y Nutrición Salvador Zubirán), el doctor Héctor Orozco llevó a cabo el primer trasplante auxiliar hepático, con un injerto de donador pediátrico, en una paciente de edad adulta; en 1985, el doctor Orozco realizó el primer trasplante ortotópico de hígado, en el mismo Instituto Nacional de la Nutrición. ${ }^{2}$ En 1988, el doctor Rubén Argüero efectuó el primer trasplante de corazón, en el Hospital de Especialidades del Centro Médico La Raza del IMSS. ${ }^{3}$ En 1989, los doctores Jaime Villalba Caloca y Patricio Santillán hicieron el primer trasplante pulmonar, en el Instituto Nacional de Enfermedades Respiratorias. ${ }^{4}$ Todos estos "primeros trasplantes" en México tuvieron lugar en la capital del país.

La obtención de un corazón con latidos efectivos con fines de trasplante transformó la cultura relacionada con la muerte cerebral: favoreció el desarrollo de los programas de trasplante, no solo de corazón sino de otros órganos y tejidos, dado que a partir de entonces se permitió utilizar material biológico. Se impulsó la procuración de órganos y tejidos provenientes de personas con muerte encefálica, lo cual en México se acompañó de sucesivas reformas y adecuaciones a la Ley General de Salud en materia de donación y trasplante de órganos y tejidos. De esta manera se abrió una oportunidad en beneficio de numerosos pacientes.

Treinta y un años después del primer trasplante de corazón, el escenario en México se caracteriza por la escasez de donaciones y trasplantes. Hay una demanda sin atender que crece año tras año, aun cuando en 2017 se registraron 255 centros autorizados para trasplante renal, lo cual convierte a nuestra nación en uno de los países con mayor número de los mismos en el mundo; respecto a otros órganos como hígado, corazón, pulmón y páncreas, es el país con más centros autorizados para trasplantes en América Latina. ${ }^{5} \mathrm{~A}$ pesar de ello, los procesos en torno a la donación y los trasplantes adolecen de falta de estandarización, calidad comparable, supervisión, análisis de los protocolos y apego estricto a los mismos, que posibiliten la valoración de los resultados en los centros autorizados con el fin de otorgar o revocar licencias cuando la opinión de un comité ad hoc así lo recomiende.

Además de los recurrentes problemas financieros, existe incertidumbre respecto a la continuidad y apoyo a los programas de trasplante por parte de las autoridades federales. Falta colaboración interinstitucional documentada en acuerdos e información de productividad
Correspondencia:

*Rubén Argüero-Sánchez

E-mail: rubenarguero@gmail.com

DOI: $10.24875 / G M M .20000070$

0016-3813/๑ 2020 Academia Nacional de Medicina de México,

CC BY-NC-ND (http://creativecommons.org/licenses/by-nc-nd/4.0/).
Fecha de recepción: 18-02-2020

Fecha de aceptación: 20-02-2020
Gac Med Mex. 2020;156:181-183

Disponible en PubMed www.gacetamedicademexico.com
tículo open access bajo la licencia artículo open access bajo la licencia 


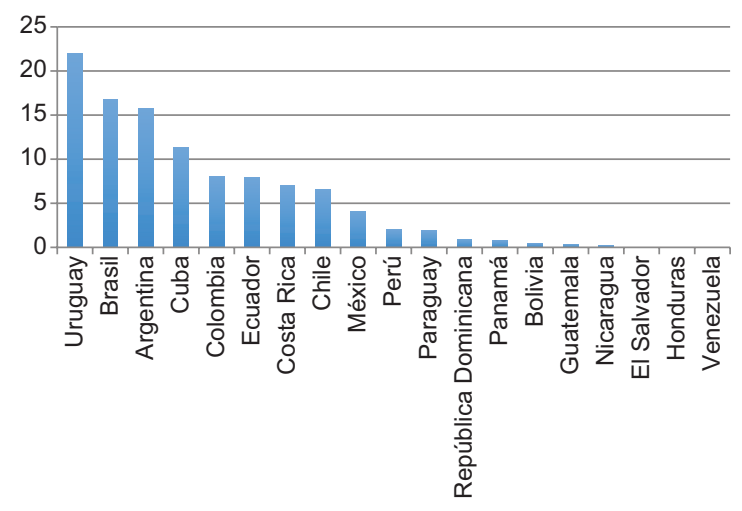

Figura 1. Tasas de donación de órganos obtenidos de donadores con muerte encefálica por millón de habitantes en diversos países de América Latina, según datos del Global Observatory on Donation and Transplantation (http://www.transplant-observatory.org/) correspondientes a 2018.

interinstitucional que incluya a los hospitales privados. En México se requiere reflexionar sobre la inequidad distributiva de las donaciones y los trasplantes, a la cual ha contribuido el fraccionamiento del Sistema Nacional de Salud, entre otros factores.

Una medida importante para corregir esa tendencia sería establecer acuerdos interinstitucionales de colaboración justos y de cara al conocimiento público, que contribuyan a minimizar la desconfianza y la posición privilegiada de algunos sectores respecto a otros. Dichos acuerdos deben crear mecanismos que en la práctica superen el fraccionamiento del Sistema Nacional de Salud y lleven hacia un sistema universal de salud, que hagan del derecho a recibir un trasplante una realidad sin menoscabo por la pertenencia a una u otra institución de salud.

Un ejercicio revelador de la productividad del Sistema Nacional de Trasplantes de México, denominado actualmente Subsistema Nacional de Donación y Trasplante (SNDT), es la comparación de las tasas de donación de órganos obtenidos de personas con muerte encefálica por millón de habitantes de diversos países latinoamericanos en 2018, información que procede del Global Observatory on Donation and Transplantation (http://www.transplant-observatory.org/). Las tasas son superiores a las de México en la mayoría de los países latinoamericanos analizados, lo cual muestra que, si bien los números absolutos de trasplantes de órganos en México se han incrementado, cuando las cifras se expresan como tasas por millón de habitantes se observa que la donación cadavérica de órganos en México no han tenido incremento significativo en los últimos 40 años, ${ }^{6}$ lo cual explica el creciente número de pacientes en espera de un órgano en nuestro país (Figura 1).

Estos elementos de análisis confluyen para caracterizar al SNDT como un sistema carente de un programa común e integral que agrupe tanto a las instituciones de salud como a los hospitales privados, y que cuente con la definición de objetivos, metas, indicadores y estrategias de crecimiento; además, no posee mecanismos de colaboración interinstitucional ni posibles contraprestaciones al personal que posibiliten la eficiencia de los integrantes del SNDT. En pocas palabras, el SNDT carece de planeación, liderazgo, programas y requiere una profunda reingeniería.

Una característica omnipresente de los programas de donación-trasplante en México ha sido la orientación hacia crear una "cultura de donación", bajo el supuesto de que el principal escollo para la realización de trasplantes es la negativa familiar; poca atención recibe la medición y evaluación de la eficiencia de los procesos y subprocesos médicos de los hospitales autorizados para estas actividades. Es necesario identificar las fallas o limitantes en el proceso de donación más allá de la negativa familiar.

La donación de órganos es un proceso que involucra diversas etapas, cada una con subprocesos en los cuales interactúan servicios, departamentos y múltiples profesionales de la salud; en el transcurso se presentan contratiempos, ineficiencia y carencias. Si bien la entrevista familiar es importante, constituye solo uno de esos subprocesos y se tiende a olvidar que los otros - de tipo médico, técnico, logístico o de gestión de recursos- pueden obstaculizar o impedir la voluntad de donar.

Se requieren cambios en la dinámica hospitalaria para mejorar los procesos de donación y no solo atribuir el bajo número de donaciones y trasplantes a la negativa de los familiares del posible donante. Hay que pugnar por programas que garanticen la calidad y faciliten la auditoría interna y externa en los hospitales y en los diversos servicios médicos involucrados, con la finalidad de su mejora continua y de eliminar los obstáculos que impiden alcanzar cifras similares a las de países exitosos en la donación y trasplante de órganos. Es evidente que es preciso hacer un alto en el camino y llevar a cabo un análisis crítico a fin de mejorar los resultados y reordenar lo que sea necesario para alcanzar los estándares internacionales. 


\section{Bibliografía}

1. Secretaría de Salud. Programa de acción: trasplantes. México: SSa; 2001.

2. Orozco-Zepeda H. Un poco de historia sobre el trasplante hepático. Rev Invest Clin. 2005;57:124-128.

3. Argüero-Sánchez R. Trasplante de corazón. Rev Invest Clin. 2005;57: 344-349.
4. Santillán-Doherty $P$, Jasso-Victoria $R$, Olmos-Zúñiga $R$, Sotres-Vega A, Argote-Greene LM, et al. Trasplante de pulmón. Rev Invest Clin. 2005;57:350-357. 5. Domínguez-Gil B, Matesanz R, editores. International figures on organ, tissue \& hematopoietic stem cell donation \& transplantation activities. Documents produced by the Council of Europe European Committee (partial agreement) on Organ Transplantation (CD-P-TO). Year 2017. EDQM; 2018;23:1-66.

6. Reyes-Acevedo R, Obrador GT, Alberú-Gómez J, Gracida-Juárez C, Madrigal JA, Aburto-Morales S. Current state and challenges for organ donation and transplantation in Mexico. Transplantation. 2019;103:648-650. 